\title{
Impact of Merger on Brand Image of Acc Cement-An Analtical Study
}

\author{
Dr. Hemanth Kumar.S. ${ }^{1}$ \& Vijayalakshmi.S. ${ }^{2}$ \\ ${ }^{1}$ Associate Professor, M P Birla Institute of Management, Bangalore, India. \\ ${ }^{2}$ Assistant Professor: M P Birla Institute of Management, Bengaluru, India.
}

\begin{abstract}
This study is envisioned to help ACC Cement Company take upon the steps to be taken care for improving its brand impact so that the development of the company keeps on nurturing. This research is an exploratory study as less study has been done on this topic. Objectives were framed with respect to the problem identified which is after the merger between the two cement giants Lafarge and Holcim how the brand impact of ACC has changed now that Holcim is the parent company of ACC Cement.

A structured questionnaire was used to achieve necessary information, to measure the brand impact and to discover the ways through which the company can augment the promotional activities of ACC cement for making its own presence strong enough in the ever competing market and to endure the hardships that manifest. It is found in this research that the brand image of ACC cements has increased after the merger between Holcim and Lafarge. Consistent quality, affordable pricing, advertisements and promotional offers for the dealers and customers of ACC Cements will increase its brand impact and growth in manifolds.
\end{abstract}

Keywords: Brand image, brand impact, organizational performance.

\section{Introduction}

There is a long history of mergers and acquisitions in the world corporate sector some which have been very successful and some failed to withstand the competition. Merging is a very essential activity which proves to be lucrative for both the companies which come into merging however there lies same amount of risk and fear in terms of sharing of information or business secrets with the other firm.

This study deals with studying the impact of merging between Lafarge and Holcim which affects the ACC Cement Company being the subsidiary of Holcim group. The name of Lafarge joining the Holcim group has a significant effect over the ACC's brand image. This study analyzes the perception of customers towards ACC after the merging of Holcim and Lafarge in terms of quality, satisfaction and service provided.

\section{Need For The Study}

This study is important to closely examine the effects of merging between equals and having a broader view on all the factors which would directly impact the company's image. Thus there is a need to study and analyze the factors like quality, service and brand image of ACC Cement Company after the merging of its parent company Holcim and Lafarge. This merger is considered as the biggest merger in the corporate world and a research study is much required to analyze the impact of merging over the brand perception, recognition and acceptance of ACC CEMENTT over dealers and the end customers.

\section{Literature Review}

Ishak Ismail, Maznah Wan Omar (2007) states the importance of brand image impact and benefits over satisfaction and loyalty, it's easier to establish effective marketing strategies if the benefits of brand image are clearly known. The study helps to understand the impact of brand image from a vantage point with reference to the customer. The inference drawn from this study helps us to understand the importance of brand image on customer loyalty and satisfaction.

Stephen L. SondohJr, Maznah Wan Omar, Nabsiah Abdul Wahid, Ishak Ismail and AmranHarun (2007) the study has demonstrated the significance of brand pictureadvantages on fulfillment and devotion. The recognizable proof of brand picture advantages of the marked item will help professionals to build up successful promoting procedures. It is essential to comprehend brand picture measurement judgments from clients' perspective, and whether these picture measurements are parallel to their recognitions, desires, needs and objectives. Knowing this, may help administrators to build up an advertising system in light of buyers' observations and implications of the product. With respect to fulfillment and dependability, it is critical for organizations to gauge clients' fulfillment keeping in mind the end goal to investigate their item or administration picture execution and whether their fulfilled clients will prescribe their marked item to others and additionally have the expectation to buy their item/benefits later on. At last, keeping in mind the end goal to 
make an effective brand, showcasing chiefs ought to be more dedicated on building brand picture, clients' fulfillment and brand faithfulness as a component of their marking system. By keeping up and fortifying the brand pictures and values, it will ideally position the brand emphatically in the brains of buyers. Along these lines, there is a need to comprehend the critical parts of three marking procedures: brand picture, brand fulfillment and brand faithfulness keeping in mind the end goal to upgrade their image advance.

Bhimrao M. Ghodeswar (2008) Paper talks about the PCDL model for building brandsin light of the writing audit and contextual investigations. Consistency of coordinated correspondences and message along the brand personality measurements focused on towards clients is basic to the accomplishment of brand-building endeavors by conveying a steady, self-strengthening brand picture. Organizations need to guarantee that the brand stays solid notwithstanding amid troublesome times and offers esteem that is reliable with the brand guarantee. The four phases recommended in PCDL demonstrate to be specific, situating the brand, conveying the brand message, conveying the brand execution, and utilizing the brand value can empower organizations to assemble solid brands.

Pradeep Kumar Gupta (2012) his study states that continuous growth and survival areimportant objectives of any organization and one process in the quest to achieve these objectives is merging and it is a very significant move in any of the organizations strategies. Merging and acquisition is done for a cause and most possibly the cause consists of financing or assisting an organization for rapid growth. The study also helps to understand the work relating to planning in any merger or acquisition and it proves to be one of the proven methods for growing profitably and maximizing shareholders wealth.

Sabin Mindrut, Adriana Manolica, Cristina Teodora Roman (2013) states that the choosing or not choosing a brand depends upon anecdotal evidence. The study aims at relating previous experience with brand identity and thus building brand image. A key factor in achieving competitive advantage is having a strong brand image.

Muhammad Faizan Malik, Melati Ahmad Anuar, Shehzad Khan, Faisal Khan (2014) The goal of this study is to audit the writing to study history of M\&A, stages, Motives and distinctive strategies utilized for measuring execution; assess the advantages and deficiencies; research whether there have been new improvements in the methods utilized in the course of the most recent couple of years. The study began surveying the M\&A writing with a plan to comprehend the important procedures and incorporating the exploration results for the advantage of directors and future specialists. The extent of the concentrate along these lines was limited to M\&A history, stages, thought processes, and techniques. To finish up, the present study demonstrates that there are various techniques for measuring procurement execution, each with its benefits and negative marks. The determination of the technique for estimation is significant to the outcomes drawn, henceforth ought to be chosen with incredible consideration.

Yi Zhang (2015) in his work helped to better understand the concept of brand image. Brand image is recognized as a force which drives brand asset. Brand image and brand equity have a strong relationship. From customers point of view the brand image impact has an influence on perception of customer.

\section{Statement Of The Problem}

There is an uplift of global competition in the cement sector with the merger of Holcim and Lafarge and because of this; there is a fear of change of customer assessment towards ACC Cement. Which happens to be the under its parent company Holcim. The merging of Holcim and Lafarge is expected to change customer perception towards ACC brand. Thus this study examines the brand impact of ACC cements.

\section{Scope Of The Study}

Merger in an activity between the organizations which are equal in competition to achieve some strategic objective and have a win-win for both the firms. The study is specifically related to the customer perception and its related factors of ACC cement after the merger of Holcim and Lafarge. The study also determines the impact of merging on ACC's brand image.

\section{Objectives Of Study}

To study assessment of Customers towards ACC CEMENT.

To examine the effect of merging by Holcim and Lafarge over cement industry.

To analyze the brand impact of ACC Cement in consumers and distributers mind. 


\section{Research Methodology}

The research type: The study is both exploratory and Descriptive

Data collection: primary and secondary information.

Primary data: A close ended questionnaire was arranged and administered to discover their inclinations or preferences. The information accumulation technique included direct meeting with the dealers and customers

Secondary data: Secondary data information was gathered from the accessible sources like diaries, articles, journals and site.

Population of the Study: This study focused on the dealers and end clients of ACC Cement Company, all the dealers and clients of ACC Cement Company of Wadi.

Sample size: A sample test of 50 clients of ACC Cement is chosen for the present study. There spondents were from various age bunches, gender and educational qualifications. For the questionnaire filling an example of 50 respondents were met from the close-by areas of Wadi like Gulbarga, Chittapur and Shahabad. Interviewed respondents were the individuals who went to the dealers store in regards to purchase the cement furthermore the dealers themselves who are a major part of the sample.

\section{Limitations Of The Study}

1. The study is limited to Wadi-Gulbarga region were the research work is proposed to be carried out.

2. The respondents may be little careless in responding to the questionnaire.

3. Respondents are at times hesitant to respond to surveys.

4. Authenticity of the response of the customer cannot be ascertained.

\section{Data Analysis}

The respondent's data is analyzed using SPSS software. The proportion of the reaction to the aggregate number of respondents is calculated and expressed in percentage form. The response or answer for the questions linked to the topic area of the research study is gathered in Likert-scale. The descriptive statistical method is also used to examine the data. The frequency distribution, cumulative percentage and regression analysis have been calculated based on the five point scale replies of the dealers and customers.

\section{HYPOTHESIS} hypotheses

There are two hypotheses to test for this study and regression analysis was used to test these two

\section{Regression analysis of first hypothesis}

It is assumed that brand image of ACC Cement is dependent on merging of Holcim and Lafarge. To test this hypothesis I conducted a regression analysis with brand image as the dependent variable and merging of Holcim and Lafarge as the independent variable. The output shows the regression equation as:

Brand image $=1.936-0.146($ merging of Holcim and Lafarge $)$

\begin{tabular}{|l|l|l|l|l|}
\multicolumn{4}{|c|}{ Model Summary } \\
\hline Model & R & R Square & Adjusted R Square & Std. Error of the Estimate \\
\hline 1 & $.349^{\mathrm{a}}$ & .122 & .103 & .46860 \\
\hline
\end{tabular}

Fig 4.29.1 model summary of first hypothesis

\section{Coefficients}

\begin{tabular}{|l|l|l|l|l|l|}
\hline \multirow{2}{*}{ Model } & \multicolumn{2}{l|}{$\begin{array}{l}\text { Un standardized } \\
\text { Coefficients }\end{array}$} & $\begin{array}{l}\text { Standardized } \\
\text { Coefficients }\end{array}$ & $\mathrm{t}$ & Sig. \\
\cline { 2 - 6 } & $\mathrm{B}$ & Std. Error & Beta & 13.248 & .000 \\
\hline (Constant) & 1.936 & .146 & & & \\
\hline $\begin{array}{l}\text { Merging between Holcim and Lafarge } \\
\text { is a good move for ACC cement }\end{array}$ & -.146 & .057 & -.349 & -2.578 & .013 \\
\hline
\end{tabular}

Fig 4.29.2 coefficients of first hypothesis 


\begin{tabular}{|c|c|c|c|c|c|}
\hline \multicolumn{6}{|c|}{ ANOVA $^{\mathbf{a}}$} \\
\hline Model & Sum of Squares & df & Mean Square & $\mathrm{F}$ & Sig. \\
\hline Regression & 1.460 & 1 & 1.460 & 6.648 & $.013^{b}$ \\
\hline Residual & 10.540 & 48 & .220 & & \\
\hline Total & 12.000 & 49 & & & \\
\hline
\end{tabular}

Fig 4.29.3 ANOVA of first hypothesis

In the analysis of variance table (ANOVA) we test the null hypothesis, i.e. there is no impact of the independent variables on the dependent variables against the alternate hypothesis, and i.e. the merging of Holcim and Lafarge does not have an impact over the brand image. The $p$ value from the ANOVA table is 0.013 which is less than the significance value of 0.05 and this leads us to fail to accept the null hypothesis, in other words we accept the alternate hypothesis and say that there exists a significant impact of merging of Holcim and Lafarge over brand image of ACC cement.

The adjusted- $\mathrm{R}^{2}$ is 0.103 . This means that the regression analysis can explain $10.3 \%$ of the data. As such, the brand image of ACC Cement is depends on merging of Holcim and Lafarge proves to be significant.

The $\mathrm{p}$ value 0.013 < significance value of 0.05 and thus we reject the null hypothesis and accept the alternate hypothesis which in this case is

: Merging of Holcim and Lafarge has a significant impact over the brand image of ACC Cement

\section{Regression analysis of second hypothesis}

It is assumed that acceptability of ACC Cement is dependent on brand recognition of ACC cement. To test this hypothesis I conducted a regression analysis with acceptability as the dependent variable and brand recognition of ACC cement as the independent variable. The output shows the regression equation as

\section{Acceptability of ACC Cement=1.340+0.300 (brand recognition)}

\begin{tabular}{|l|l|l|l|l|}
\multicolumn{5}{|c}{ Model Summary } \\
\hline Model & R & R Square & Adjusted R Square & Std. Error of the Estimate \\
\hline 1 & $.335^{\mathrm{a}}$ & .112 & .094 & 1.06046 \\
\hline
\end{tabular}

Fig 4.30.1 model summary of second hypothesis

\section{Coefficients $^{\mathrm{a}}$}

\begin{tabular}{|c|c|c|c|c|c|c|}
\hline \multirow{2}{*}{\multicolumn{2}{|c|}{ Model }} & \multicolumn{2}{|c|}{$\begin{array}{l}\text { Un standardized } \\
\text { Coefficients }\end{array}$} & $\begin{array}{l}\text { Standardized } \\
\text { Coefficients }\end{array}$ & $\mathrm{t}$ & Sig. \\
\hline & & $\mathrm{B}$ & Std. Error & Beta & & \\
\hline & (Constant) & 1.340 & .328 & & 4.083 & .000 \\
\hline 1 & $\begin{array}{l}\text { Has merging between } \\
\text { Holcim and Lafarge made } \\
\text { ACC a recognizable brand } \\
\text { in cement industry? }\end{array}$ & .300 & .122 & .335 & 2.466 & .017 \\
\hline
\end{tabular}

Figure 4.30.2 coefficients of second hypothesis

ANOVA ${ }^{\mathbf{a}}$
\begin{tabular}{|l|l|l|l|l|l|l|}
\hline Model & & Sum of Squares & df & Mean Square & F & Sig. \\
\hline \multirow{3}{*}{1} & Regression & 6.840 & 1 & 6.840 & 6.082 & $.017^{\mathrm{b}}$ \\
\cline { 2 - 8 } & Residual & 53.980 & 48 & 1.125 & & \\
\cline { 2 - 8 } & Total & 60.820 & 49 & & & \\
\hline
\end{tabular}

Fig 4.30.3 Anova of second hypothesis

In the analysis of variance table (ANOVA) we test the null hypothesis, i.e. There is no impact of the independent variables on the dependent variables against the alternate hypothesis, i.e. the Brand recognition does not influence the acceptability. The $\mathrm{p}$ value from the ANOVA table is 0.017 which is less than the significance value of 0.05 and this leads us to fail to accept the null hypothesis, in other words we accept the alternate hypothesis which says that Brand recognition of ACC Cement after the merger of Holcim and Lafarge has a positive influence over its acceptability.

The adjusted- $\mathrm{R}^{2}$ is 0.904 . This means that the regression analysis can explain $9.4 \%$ of the data.. As such, Brand recognition of ACC Cement after the merger of Holcim and Lafarge has a positive influence over its acceptability proves to be significant.

The $\mathrm{p}$ value 0.017 < significance value of 0.05 and thus we reject the null hypothesis and accept the alternate hypothesis which in this case is

(2) = Brand recognition of ACC Cement after the merger of Holcim and Lafarge has apositive influence over its acceptability. 


\section{Summary Of Findings}

Majority of the respondents agree that consistent quality is delivered by ACC cement after the merger. The merger between Holcim and Lafarge is a good move for ACC cement and respondents opined that in general Merging between organizations is effective

Majority of the respondents agree that Service quality has improved of ACC cement after the merger which is of a good omen for the organization.

From research it is evident that One of the importance factor which enables the respondents to be dealer of ACC cement is quality of product and majority of the respondents find it most important. Company policy being one of the factors that enables them to be a dealer of ACC cement

From the survey it was found that the dealers don't care much about the promotional schemes and rate it not important for becoming a dealer with ACC. And Majority of the respondents agreed to continue being associated with ACC cement even after merger.

Majority of the respondents disagree to the response of any changes in the after sales service of the ACC cement. The after sales service has changed very minimal and can be considered insignificant, which means the after sales service is satisfactory. Pricing is one factor which respondents are unsatisfied with ACC cement. The pricing of ACC cement is quiet high when compared to their competitors.

Majority of the respondents disagreed to the statement whether they foresee any changes in practices towards dealers and customers by ACC cement after the merging between Holcim and Lafarge. The respondents do not anticipate any changes in the practices by organization. Majority of the respondents find ACC cement better than the other cement brands.

Special promotional activities taken up by ACC Cement to build the brand image are taken up by the company and majority of the respondents agree to this statement. Majority of the respondents agree about the high acceptability of ACC cement.

Advertisements are the main source and responded by the majority of the respondents when they try to recall the brand ACC.

Majority of the respondents agree that merging between Holcim and Lafarge made ACC a recognizable brand in cement industry. The merger has recognized ACC as a high end brand in the cement sector.

Majority of the respondents agree management of suppliers and dealers has improved after the merging. Advertisements of ACC Cement increased after the merge, majority of the respondents agree to this statement. Other promotional activities have also increased by ACC cement after the merger.

Majority of the respondents find that there is increase in promotional activities of the competitors. Newspaper in the medium how majority of the respondents got to know about ACC brand. The regression analysis on the first hypothesis found that there is a positive impact of merging of Holcim and Lafarge over the brand image of ACC Cement The regression analysis on the second hypothesis found that there is a positive impact of brand recognition over the acceptability.

\section{Conclusions}

Merger between the organizations have been prominent in the business world and proved to be a significant move for the both the organizations which come to this agreement. This mutual consent between organizations has fetched large amount of profits and quenched the completion of the objectives set accordingly for a win-win situation.

There is a humongous resolution of problems which occur, impact of the merger is seen in the activities of the competitor organizations that get intimidated by this move and try to make their mark or stand by deploying new and improved strategies to counter the merger moves. This study revealed the impact of ACC brand after the merger between Holcim and Lafarge that the competitors have increased their promotional activities to counter this mergence. There is a high acceptability of ACC cement because of the quality delivered by ACC in its every grade of cement be it 43 grade cement, 53 grade cement, Portland cement, Portland slag cement and ready mix cement. The service quality is also delivered consistently at a satisfied level by the company which adds to its impact over the customers.

The dealers are also satisfied with the practices followed by the company and the advertisements have also increased since the merger between Holcim and Lafarge, trust is also increased on ACC cement. The augment in various promotional activities by ACC cement has allured the customers and ACC has a stronghold in the customers mind as a trusted brand among the other competitors. People are getting aware of the brand by its high visibility in advertisements whichwere to be hardly seen before the merger. Thus the merger between Holcim and Lafarge has increased the brand awareness of ACC cements.

The hypothesis testing proved to be significant in both the tests and can be concluded that the merger between Holcim and Lafarge influences the brand image positively and the brand image of ACC cement depends on the merger. Thus, the merger has increased the brand image of ACC cement. 
The second hypothesis proved to be significant as well and can be concluded that the brand recognition has a positive influence over the acceptability of ACC cement and that the acceptability depends on ACC being a recognizable brand. A direct impact can be seen of brand recognition over its acceptability that people accept a brand which is recognized well.

\section{Suggestions}

The following suggestions are provided by my analysis of the study to the company over various aspects taken from the statistical analysis of the responses from the questionnaire and the inferences drawn:

$\square \quad$ Consistent quality of the product should be delivered by the company and shall not be ignored for quality of ACC cement builds trust of dealers and end customers.

Promotional schemes should be provided by the company for there are few attractive schemes for the dealers and wholesalers and there always stands a chance to lose them to other company with better promotional schemes for them.

$\square \quad$ After sales service could be improved by the company, there is a response of consistent and no change in the service also satisfaction level with this after sales service is moderate and to retain the customers and dealers company could improve the after sales service so that the customers become advocates of the company and be the word of mouth and recommenders for others.

$\square \quad$ Pricing could be reduced a little because customers feel it quiet high. The cost can be cut by reducing the excess manpower in the company.

Advertising could be increased to gain higher market share.

- ACC as a brand got added value by the merger between Holcim and Lafarge where Holcim being the parent company of ACC cement. This merger has increased the acceptability of ACC cement and building brand recognition could be a lucrative move for ACC cement by promotions and catering the middle class and lower middle class segment.

\section{References}

[1]. Muhammad Faizan Malik, Melati Ahmad Anuar, Shehzad Khan and Faisal Khan, (2014), Mergers and Acquisitions: A Conceptual Review, International Journal of Accounting and Financial Reporting ISSN 2162-3082 Vol. 4, No. 2

[2]. Sabin Mindrut, Adriana Manolica, Cristina Teodora Roman, (2015), Building brands identity, Procedia Economics and Finance 20 (2015 ) $393-403$

[3]. Bhupesh Malhotra and Dr. Vandana Sharma, (2013), Literature Review for Impact of Mergers \& Acquisitions on Human Resource Practices in IT Industry, International Journal of Emerging Research in Management \&Technology ISSN: 2278-9359 (Volume-2, Issue-6)

[4]. Raymond R. Tjandrawinata1 and andDestrina Grace Simanjuntak, (2014), The Impact of Mergers and Acquisitions in ResearchBased Pharmaceutical Companies on Productivity

[5]. Yi Zhang, (2015), The Impact of Brand Image on consumer behavior: A Literature Review, Open Journal of Business and Management,3, 58-62

[6]. Bhimrao M. Ghodeswar, (2008), Building brand identity in competitive markets: a conceptual model, Journal of Product \& Brand Management Volume 17 · Number 1 · 2008 · 4-12

[7]. Stephen L. SondohJr, Maznah Wan Omar, Nabsiah Abdul Wahid, Ishak Ismail, AmranHarun, (2007), The effect of brand image on overall satisfaction and loyalty intention in the context of color cosmetic, Asian Academy of Management Journal, Vol. 12, No. 1, 83-107

[8]. Pradeep Kumar Gupta, (2012), Mergers and acquisitions (m\&a): the strategic concepts for the nuptials of corporate sector, Innovative journal of business and management ISSN No. 2277-4947

\section{Webilography}

[9]. https://en.wikipedia.org/wiki/LafargeHolcim

[10]. https://en.wikipedia.org/wiki/Holcim

[11]. https://en.wikipedia.org/wiki/Lafarge_(company)

[12]. 4)http://www.lafargeholcim.com/holcim-and-lafarge-formally-notify-proposed-merger-european-commission

[13]. www.mpbim.com/proquest

[14]. www.acclimited.com 